\title{
LESSONS LEARNED FROM SOFT COMPUTING APPLICATIONS AT SCK•CEN
}

\author{
Da RUAN ${ }^{1,2}$ \\ ${ }^{1}$ Belgian Nuclear Research Centre $(S C K \bullet C E N)$ \\ Boeretang 200, $2400 \mathrm{Mol}$, Belgium \\ City, State ZIP/Zone, Country \\ druan@sckcen.be \\ ${ }^{2}$ Department of Applied Mathematics and Computer Science \\ Ghent University, 9000 Gent, Belgium \\ Da.ruan@ugent.be
}

Received: 25-11-2009
Accepted: 28-05-2010

\begin{abstract}
By answering "what is soft computing?" we briefly examine four research projects of soft computing applications at the Belgian Nuclear Research Centre (SCK•CEN) from the practical point of view. We draw lessons learned from the examined projects including reactor control, cost estimation, energy policy, and nuclear safeguards. We conclude that soft computing techniques are new computer information processing methods that are complementary to all traditional approaches for real-problem solving and that present great challenges in practice.
\end{abstract}

Keywords: Soft computing, computational intelligence, control, decision making, FLINS.

\section{Introduction}

At the $8^{\text {th }}$ International FLINS conference on Computational Intelligence in Decision and Control (Madrid, Spain, 21-24 September 2008), Magdalena delivered a plenary lecture on "What is Soft Computing? Revisiting possible answers" ${ }^{1}$ and extended his paper into this special issue. ${ }^{2}$ After having given and analyzed different definitions of soft computing by different authors over different time periods, Magdalena skillfully summarized soft computing has various aspects such as "as the mixture of several pre-existing techniques," "as opposite to hard computing," and "as a tool to cope with uncertainty and imprecision". From the increased numbers of workshops, conferences, journals, and research papers related to the topic of soft computing, we see the research topic of soft computing is still popular, especially in computer science and artificial intelligence. More than a decade ago, we also discussed the same question on "what is soft computing?" ${ }^{3}$ In the meantime, we have also carried out a few research projects, namely, nuclear reactor control, large projects' cost estimation, nuclear safeguards information management, and energy policy study to answer the question "what is soft computing?" In this paper, we briefly report the above-mentioned projects at the Belgian Nuclear Research Centre (SCK•CEN) and draw the lesson learned from soft computing applications ranging from control to decision making. The rest of the paper is organized as follows. We first present the FLINS forum - Fuzzy Logic and Intelligent technologies in Nuclear Science at SCK $• \mathrm{CEN}$ and related research projects in Section 2. We then draw 
lesson learned from the $\mathrm{SCK} \cdot \mathrm{CEN}$ projects on soft computing application in Section 3. And we finally conclude that soft computing techniques are new computer information processing methods that complementary to all traditional approaches for realproblem solving and that present great challenges in practice in Section 4.

\section{FLINS projects at $\mathrm{SCK} \cdot \mathrm{CEN}$}

FLINS, an acronym originally for Fuzzy Logic and Intelligent Technologies in Nuclear Science, ${ }^{4}$ has been launched in line with the SCK $\cdot C E N$ 's objective to give $\mathrm{PhD}$ and Postdoc researchers the opportunity to carry out future-orientated research. FLINS was initially built within one of the above-mentioned Postdoc positions. Now 16 years later FLINS has been extended to Applied Computational Intelligence to advance the theory and applications of soft computing in decision making and control for complex systems. The principal task of FLINS is to conduct research on computational intelligence systems for solving intricate problems pertaining to nuclear/power research and related complex systems. The terminologies of soft computing, artificial intelligence, and computational intelligence are having the same meanings ${ }^{5,6}$ in the contents of FLINS activities.

\subsection{The BR1 reactor with fuzzy logic control}

The need for on-line reactor operator support systems has become evident after the Three-Mile-Island accident in 1979. Since then, considerable attention has been paid by the engineering, scientific, economical and political communities and society at large to prevent this type of events by using State-of-the-Art artificial intelligence techniques or soft computing techniques. ${ }^{7,8,9}$ Among the techniques available today, the use of fuzzy control as a means of expressing linguistic expressions mathematically, has been recently applied to nuclear reactor control.

In an R\&D project on fuzzy control to the BR1 (The Belgian Reactor 1) for controlling the power level of a nuclear reactor, the study was intended to assess the applicability of fuzzy control in this domain. The final goal was to develop an optimized and intrinsically safe controller. During the project, a fuzzy logic controller was proposed ${ }^{10}$ and first tested by comparing it with the classical controller of BR $1 .{ }^{11}$ In the next step the BR1 reactor at $\mathrm{SCK} \cdot \mathrm{CEN}$ was used as a test bed to implement a PLC-based hardware controller. ${ }^{12}$ The BR1 reactor is internationally regarded as a nuclear calibration reference. It therefore provides an excellent environment for this type of experiments, because over the years considerable knowledge of the static and dynamic properties of the reactor has been accumulated.

The project (1995-1999) aimed at investigating the added value and technical limits of fuzzy control for nuclear reactor operations. The progress made in these experiments including closed-loop experiments has been published. ${ }^{13}$ By July 1998, a permission to carry on the closed-loop test at BR1 under fuzzy control was obtained. The very first closed-loop experiment was successfully carried out in September 1998. It should be noted that that experiment and later other closed-loop experiments were only on the steady-state operation. The project as a feasibility study on fuzzy control to nuclear reactor control fulfilled its function. Lately, a series of simulated experiments has been carried out using adaptive fuzzy control, ANNs and GAs to find out which strategies are most promising for further research and future application in nuclear reactor operation in a cooperation project with the Mexican Nuclear Research Centre (ININ) on AI-based intelligent control for nuclear reactor operation under the partial support of the National Council for Science and Technology of Mexico (CONACYT). ${ }^{14,15,16}$ However, a real implementation of soft computing related modern techniques to nuclear reactors is still rare. Historical speaking, only the MIT research reactor, ${ }^{17}$ the FUGEN heavy water reactor ${ }^{18}$ and the BR1 research reactor ${ }^{13}$ have conducted part of real implementation of fuzzy control techniques. However, all of those projects are stopped/finished. The reason for stopping/finishing such projects, besides safety regulation ${ }^{19}$ is considerable efforts on R\&D costs. This somehow explains why there is no real implementation of such systems in today's nuclear power plants in the world. ${ }^{20,21}$

\subsection{Cost estimation for a lager-scale nuclear project}

Cost estimation for large projects can be difficult because of many complex factors and uncertainties involved. It is often the case that only very rough guesses of actual costs may be provided. Facing with various types of uncertainties in the cost estimation of one specific large project called Myrrha, which is an Accelerator Driven System (ADS) under development 
at $\mathrm{SCK} \cdot \mathrm{CEN}$ to serve as a basis for the European experimental ADS to provide protons and neutrons for various R\&D applications (http://www.sckcen.be/myrrha), we have experienced intelligent decision systems (ISD) ${ }^{22,23}$ for this project.

Potential costs for the Myrrha project at this stage might include: (1) the construction of the Myrrha machine and its related components, (2) R\&D activities, (3) feasibility and pre-design studies, and (4) licensing. Just for the item (1), all possible expenses are far from detailed at this stage and the expenses are those that would be incurred after the decision to construct the Myrrha machine (around the end of 2009). This means that all technical problem areas (e.g., spallation source, accelerator, robotics, fuel, and instrumentation) are given a reasonably satisfactory solution and that the predesign has come to a point that no technical major problems are to be expected any more.

There are many ways to estimate the cost of the machine. ${ }^{24,25}$ Classically, the costs of the abovementioned item (1) are separated in a coarse way into: (i) material cost, (ii) engineering cost, (iii) manufacturing costs, and (iv) other costs (e.g., costs for transport, quality assurance, special treatments, and purchase of small components). It is not always clear when this distinction is to be made and this separation can be used in a more arbitrary way to facilitate the cost estimation of a particular item. For instance, the reactor vessel is not a complex component and one can (more or less) easily estimate its cost by adding the material, the engineering and the manufacturing costs and if necessary some other costs (e.g., ultrasonic control of welds and thermal treatment). On the other hand some components (e.g., bearings, motors, and drives) are industrially available and for those components the cost separation is useless. In those cases, only the expected purchase price is considered as "other costs".

However, it is very difficult to estimate the price all at once as we are just in the pre-design phase without any detailed technical drawing of any part of the machine. So, all estimations are more or less rough guesses under various uncertainties. Especially estimating the input parameters may be difficult at early stages of the design due to lack of data or insight. In addition, historic data for construction are not always accessible and more importantly are often unreliable. To overcome data difficulties, a probabilistic technique, usually the Monte Carlo simulation (MCS), ${ }^{26}$ may be employed, where it is required to determine a probability distribution function (PDF) for every uncertain variable to carry out an MCS. Such functions are best derived from statistical analysis of significant data. But, as mentioned previously, historic data are sparse; therefore it is questionable whether statistically meaningful PDFs can be derived.

With the help of IDS, a software package designed to assist multi-attribute decision analysis under uncertainties, a better cost estimation for the Myrrha machine has been carried out as a result of the cooperation between $\mathrm{SCK} \cdot \mathrm{CEN}$ and The University of Manchester. $^{27}$ IDS, based on evidential reasoning ${ }^{23}$ provides a decision process more transparent and informative with an unprecedented capability in handling uncertainties and friendly user interfaces for problem structuring, information collection, and data presentation in both graphical and text formats. It accepts input data (cost estimate for each decomposed item in the hierarchy) with or without uncertainties: quoted costs from suppliers, rough guess with a range, and cost estimate from a group of experts whose estimates may not agree with each others, cost estimates with probability uncertainty or subjective uncertainty. The case study on the Myrrha project illustrated the success of intelligent decision analysis for cost estimations of large scale engineering projects with various uncertainties. ${ }^{28}$

\subsection{Multi-criteria group decision support energy policy study}

The Belgian parliament in 2003 enacted a law to progressively phase out existing nuclear power plants. Decision has caused contestation among a number of historically active social groups in the energy policy debate. Referring to this relatively controversial climate, the research reported in Ref. 29 stretches the scope of the debate outside the boundaries of political (parliamentary) decision making. Among many interesting issues related to nuclear energy and sustainable development, the question whether nuclear electricity generation can contribute to the transition towards a sustainable energy future for Belgium, and, if so, under which conditions. Laes argued that scientific contributions to sustainable development do not follow the linear procedure from empirical knowledge production to policy advice. Instead, they consist of problem-oriented combinations of explanatory, 
orientation- and action-guiding knowledge. Society and policy makers not only have to be provided with actionguiding knowledge, but also with an awareness of the manner in which this knowledge is to be interpreted, and where the inevitable uncertainties lie. Since the sustainability question is inherently multi-dimensional, participation of social groups is an essential element of a strategy aimed at sustainable development. Multicriteria decision support provides a platform to accommodate a process of arriving at a judgment or a solution for the sustainability question based on the input and feedback of multiple individuals. At the same time in practice, multi-criteria decision problems at tactical and strategic levels often involve fuzziness in their criteria and decision makers' judgments. Due to the multi-dimensional nature of the sustainability question, we believe that the evaluation of strategic policy options has to be based on procedures that explicitly recognize the integration of a broad set of (possibly conflicting) points of view. Multi-criteria evaluation techniques can in principle provide an appropriate policy framework for setting long-term strategic priorities.

Multi-criteria decision making (MCDM) with linguistic variables, commonly known as fuzzy multicriteria decision making (FMCDM), has been one of the fastest growing areas in decision making and operations research during the last three decades. ${ }^{30,31,32}$ The motivation for the development of FMCDM is the large number of criteria that decision makers are expected to incorporate in their actions and the difficulty of expressing decision makers' opinions by crisp values in practice. $^{33,34,35}$ Group decision making takes into account how people work together in reaching a decision. Uncertain factors often appear in a group decision process, namely with regard to decision makers' roles (weights), preferences (scores) for alternatives (scenarios), and judgments (weights) for criteria (indicators). ${ }^{36}$ In this project, we argued in favor of the use of a fuzzy-logic based multi-criteria group decision (FMGDM) support tool for long-term scenarios of Belgian energy policy. The FMCGDM algorithm deals with uncertain factors to a multi-level, multicriteria decision to generate a group satisfactory decision. The solution is in the most acceptable degree of the group for this study. With the help of the FMCGDM algorithm, a software package designed to assist multi-criteria decision analysis under uncertainties, a long-term scenarios study for Belgian energy policy has being carried out as a result of the cooperation between $(\mathrm{SCK} \cdot \mathrm{CEN})$ and University of Technology, Sydney (UTS). ${ }^{37}$ The FMCGDM tool can indeed provide more insight into the nature of these conflicts by providing systematic information for the social-economic analysis of nuclear energy systems in particular and for any complex evaluation systems in general.

\subsection{Nuclear safeguards evaluation}

Nuclear safeguards are a set of activities by which the International Atomic Energy Agency IAEA seeks to verify that a State is living up to its international undertakings not to use nuclear programs for nuclear weapons purposes. The safeguards system is based on assessment of the correctness and completeness of the State's declarations to the IAEA concerning nuclear material and nuclear-related activities. As a part of the efforts to strengthen international safeguards, including its ability to provide credible assurance of the absence of undeclared nuclear material and activities, IAEA makes use of increased amounts and types of information on States' nuclear and nuclear related activities. This information includes declarations provided by States, information collected by IAEA and other information available to IAEA.

The Physical Model $^{38}$ used by IAEA is a technical tool for the implementation of an enhanced information analysis. It includes all the main activities that may be involved in the nuclear fuel cycle from the source material acquisition to the production of weaponsusable material. It contains detailed narratives describing every known process for accomplishing each given nuclear activity represented in the fuel cycle. The Physical Model identifies and describes indicators of existence or development of a particular process. The indicators include especially designed and dual-use equipment, nuclear and non-nuclear materials, technology/training/R\&D, other observables, and byproducts/effluents. The specificity of each indicator is designated to a given nuclear activity and is used to determine the strength of an indicator. An indicator that is presented only if the nuclear activity exists or is under development, or whose presence is almost always accompanied by certain nuclear activity is a strong indicator of the activity. Conversely, an indicator that is present for many other reasons, or is associated with 
many other activities, is a weak indicator. In between are medium indicators.

Among the activities described in the Physical Model for nuclear fuel cycle, every activity is structured by means of processes that may alternative or complimentary to each other. The existences of the processes are determined by the indicators. More than 900 indicators are defined in the Physical Model to make the final decision of existence of nuclear programs for nuclear weapons.

Evaluation of the indicators is conducted by the IAEA experts on the basis of their analysis of the available information sourced from declaration of States, on-site inspections, non-safeguards IAEA databases, and open sources such as Internet and newspapers. The evaluations are made in different time periods and by different experts. Therefore the indicator evaluations of the experts for different periods are to be aggregated to make a final decision. Since this process contains subjective judgments of the experts and aggregation of multiple evaluations, it is complicated under various uncertainties.

We have been conducting this project since 2000 from linguistic assessment approaches, ${ }^{39,40}$ ordinal linguistic terms and 2-tuple representation approaches, ${ }^{41,42}$ belief rule-base inference methodologies, ${ }^{43,44}$ and cumulative belief-degree approaches $^{45}$ to handle hybrid uncertain information in nuclear safeguards evaluation process. It was considered advantageous to have a sound and reliable mathematical framework available that provides a basis for synthesis across multidimensional information of varying quality, especially to deal with information that is not quantifiable due to its nature, and that is too complex and ill-defined, for which the traditional quantitative approach (e.g., the statistical approach) does not give an adequate answer.

\section{Lessons learned}

Among the above-examined four projects on soft computing applications at $\mathrm{SCK} \cdot \mathrm{CEN}$, we have learned from the reactor control project and other related nuclear systems ${ }^{46,47}$ that soft computing techniques present tremendous challenges in safety related complex systems as they are still questionable on validation of the complex program, reliability in a real application domain, understanding without "black-box," efforts in $\mathrm{R} \& \mathrm{D}$, and license aspects. As long as those issues cannot be resolved, we won't be able to go ahead for soft computing applications in such complex systems.

At the same time, we have also learned from the three decision making projects or other topics such as risk analysis, ${ }^{48,49}$ sensory evaluation ${ }^{50,51}$ and policy decision $^{52,53}$ that soft computing techniques provide with additional tools to deal with effectively various uncertainties. However, the foundation of soft computing techniques is not yet at its final stage as many theoretical issues are under development. Especially, we can specify a long way for us to go on the issues related to implementation, demonstration, standardization, and commercialization of soft computing techniques in our real complex decision support systems.

\section{Concluding remarks}

In this paper, we examined some of the real world problems by applying soft computing techniques. From the lessons we have so far learned, we may not necessarily discuss the detailed definition of various soft computing techniques. However, we can remark that soft computing or computational intelligence techniques are new computer information processing methods that are complementary to all traditional approaches for realproblem solving and that present great challenges in practice.

\section{References}

1. D. Ruan, J. Montero, J. Lu, L. Martinez, P. D'hondt, E.E. Kerre, Computational Intelligence in Decision and Control, the Proceedings of FLINS2008, World Scientific, Singapore, 2008

2. L. Magdalena, What is soft computing? Revisiting possible answers, Int. J. of Computational Intelligent Systems, 3 (2), 2010

3. X. Li, D. Ruan, A.J. van der Wal, Discussion on soft computing at FLINS'96, Int. J. of Intelligent Systems, 13 (2/3), 287-300 (1998)

4. D. Ruan, P. D'hondt, P. Govaerts, E.E. Kerre, Eds, Fuzzy Logic and Intelligent Technologies in Nuclear Science, the Proceedings of FLINS'94, World Scientific, Singapore, 1994

5. D. Ruan, Ed, Intelligent Hybrid Systems: Fuzzy Logic, Neural Networks, and Genetic Algorithms, Kluwer Academic Publishers, Boston, USA, 1997

6. D. Ruan, G. Chen, E.E. Kerre, G. Wets, Eds., Intelligent Data Mining, Springer, Heideberg, 2005 
7. D. Ruan, P.F. Fantoni, Eds, Power Plant Surveillance and Diagnostics-Applied Research with Artificial Intelligence, Springer, Heidelberg, 2002

8. D. Ruan, P.F. Fantoni, Introduction: intelligent systems for process monitoring and diagnosis, Int. J. of Intelligent Systems, 17 (8), 717-721 (2002)

9. D. Ruan, Ed, Fuzzy Systems and Soft Computing in Nuclear Engineering, Physica-Verlag, Heidelberg, 1999

10. D. Ruan, A.J. van der Wal, Controlling the power output of a nuclear reactor with fuzzy logic, Information Sciences, 110, 151-177 (1998)

11. X. Li, D. Ruan, Comparative study of fuzzy control, PID control, and advanced fuzzy control for simulating a nuclear reactor operation, Int. J. of General Systems, 29 (2), 263-279 (2000)

12. D. Ruan, Implementation of adaptive fuzzy control for a real time control demo-model, Real-Time Systems, 21, 219-239 (2001)

13. D. Ruan, Initial experiments on fuzzy control for nuclear reactor operations at the BR1, Nuclear Technology, 143 (2), 227-240 (2003)

14. J.S. Benitez-Read, D. Ruan, International cooperation on control for safe operation of nuclear research reactors, Progress in Nuclear Energy, 46 (3-4), 309-320 (2005)

15. J.S. Benitez-Read, D. Ruan, M. Najera-Hernanbez, Benjamin Pérez-Clavel, J.O. Pacjeco-Sotelo, R. LopezCallejas, Comparison between a continuous and a discrete method for the aggregation and defuzzification stages of a TRIGA reactor power fuzzy controller, Progress in Nuclear Energy, 46 (3-4), 321-327 (2005)

16. J.S. Benítez-Read, T. Rivero-Gutiérrez, D. Ruan, C.L. Ramírez-Chávez, R. López-Callejas, J.O. PachecoSotelo, User interface for intelligent control schemes in a TRIGA Mark III reactor, Int. J. Nuclear Knowledge Management, 2 (3), 268-284 (2007)

17. J.A. Bernard, Use of a rule-based system for process control, IEEE Control System. Mag., 8, 3-13(1988)

18. T. Iijima, Y. Nakajima, Y. Nishiwaki, Application of fuzzy logic control systems for reactor feedwater control, Fuzzy Sets and Systems, 74, 61-72(1995)

19. J.G. Williams, W.C. Jouse, Intelligent control in safety systems: criteria for acceptance in the nuclear power industry, IEEE Transactions on Nuclear Science, 40, 2040-2044 (1993)

20. D. Ruan, Intelligent systems in nuclear applications, Int. J. of Intelligent Systems, 13 (2/3), 115-125 (1998)

21. D. Ruan, J.S. Benitez-Read, Fuzzy control for nuclear reactor operation - strengths, weaknesses, opportunities and threats, Journal of Intelligent and Fuzzy Systems, 16 (4), 289-295 (2005)

22. J.B. Yang, M.G. Singh, An evidential reasoning approach for multiple attribute decision making with uncertainty, IEEE Transactions on Systems, Man, and Cybernetics, $\mathbf{2 4}$ (1), 1-18 (1994)

23. J.B. Yang, D.L. Xu, Nonlinear information aggregation via evidential reasoning in multi-attribute decision analysis under uncertainty, IEEE Transactions on
Systems, Man, and Cybernetics Part A: Systems and Humans, 32 (3), 376-393 (2002)

24. P.F. Ostwald, Construction Cost analysis and Estimating, Prentice-Hall International, 2001

25. J. Sweeting, Project Cost Estimating: Principles and Practice, Institution of Chemical Engineers, 1997

26. R.Y. Rubinstein, Simulation and the Monte Carlo method, Wiley, 1981

27. D. Ruan, D. Maes, H. Aït Abderrahim, J. Liu, L. Xu, J.B. Yang, Cost estimations for large scale engineering projects under various uncertainties, Joint EUSFLATLFA2005, Barcelona, Spain, Sept. 7-9, 2005, CD-rom Proceedings pp. 955-960

28. D. Ruan, T. Li, Uncertainty analysis via aggregation operators for cost estimation in a lager scale nuclear project, Int. J. Nuclear Knowledge Management, 2 (4), 375-395 (2007)

29. E. Laes, Nuclear Energy and Sustainable Development, $\mathrm{Ph} . \mathrm{D}$. Thesis, Catholic University of Leuven, Leuven, Belgium, 2006

30. M. Marimin I. Hatono, H. Tamura, Linguistic labels for expressing fuzzy preference relations in fuzzy group decision making. IEEE Transactions on Systems, Man, and Cybernetics, 28 (2), 205-217 (1998)

31. I. Nishizaki, F. Seo, Interactive support for fuzzy tradeoff evaluation in group decision-making. Fuzzy Sets and Systems, 68(3), 309-325 (1994)

32. R.R. Yager, L.A. Zadeh (Eds.), An Introduction to Fuzzy Logic Applications in Intelligent Systems, Kluwer Academic Publisher, Boston, 1992

33. L.A. Zadeh, The concept of a linguistic variable and its applications to approximate reasoning. Part I, Information Sciences, 8 (3), 199-249 (1975)

34. L.A. Zadeh, The concept of a linguistic variable and its applications to approximate reasoning. Part II, Information Sciences, 8 (4), 301-357 (1975)

35. L.A. Zadeh, The concept of a linguistic variable and its applications to approximate reasoning. Part III, Information Sciences, 9 (1), 43-80 (1975)

36. J. Lu, G. Zhang, D. Ruan, and F. Wu, Multi-Objective Group Decision Making - Methods, Software and Applications with Fuzzy Set Technology, Imperial College Press, London, 2007

37. D. Ruan, J. Lu, E. Laes, G. Zhang,, J. Ma, G. Meskens, Multi-criteria group decision support with linguistic variables in long-term scenarios for Belgian energy policy, Journal of Universal Computer Science, 16 (1), 103-120, 2010

38. IAEA, Physical Model, IAEA Department of Safeguards, SRT-314, 1999

39. J. Liu, D. Ruan, R. Carchon, Synthesis and evaluation analysis of the indicator information in nuclear safeguards applications by computing with words, Int. J. Appl. Math. Comput. Sci., 12 (3), 449-462 (2002)

40. D. Ruan, J. Liu, R. Carchon, Linguistic assessment approach for managing nuclear safeguards indicator 
information, Int. J. of Logistics Information Management, 16 (6), 401-419 (2003)

41. L. Martinez, J. Liu, D. Ruan, J.-B. Yang, Dealing with heterogeneous information in engineering evaluation processes", Information Sciences, 177, 1533-1542 (2007)

42. F. Herrera, L. Martinez, A model based on linguistic 2tuples for dealing with multigranular hierarchical linguistic contexts in multi-expert decision making, IEEE Transactions on Systems, Man, and Cybernetics-Part B: Cybernetics, 31(2), 227-234 (2001)

43. J. Liu, D. Ruan, H. Wang, L. Martiney, Improving nuclear safeguards evaluation through enhanced belief rule-based inference methodology, Int. J. Nuclear Knowledge Management, 3 (3), 312-339 (2009)

44. J. Liu, J.B. Yang, D. Ruan, L. Martinez, J. Wang, Selftuning of fuzzy belief rule bases for engineering system safety analysis, Annals of Operations Research 163 (1), 143-168, 2008

45. O. Kabak, D. Ruan, A cumulative belief degree-based approach for missing values in nuclear safeguards evaluation, IEEE Transactions on Knowledge and Data Engineering, 2010 (in press)

46. D. Roverso, D. Ruan, Enhancing cross-correlation analysis with artificial neural networks for nuclear power plant feedwater flow measurement, Real-Time Systems, 27 (1), 85-96 (2004)

47. D. Ruan, D. Roverso, P.F. Fantoni, J.I. Sanabrias, J.A. Carrasco, L. Fernandez, Integrating cross- correlation techniques and neural networks for feedwater flow measurement, Progress of Nuclear Energy, 43 (1-4), 267 $274(2003)$

48. C. Huang, D. Ruan, Fuzzy risks and an updating algorithm with new observations, Risk Analysis, 28 (3), 681-694 (2008)

49. D. Ruan, J. Kacprzyk, M. Fedrizzi, Eds, Soft Computing in Risk Evaluation and Management-Applications in Technology, Environment and Finance, Physica-Verlag, Heidelberg, 2001

50. D. Ruan, X. Zeng, Eds., Intelligent Sensory Evaluation, Springer, Heidelberg, 2004

51. X. Zeng, D. Ruan, L. Koehl, Intelligent sensory evaluation: concepts, implementations, and applications, Mathematics and Computers in Simulation, 77 (5-6), 443-452 (2008)

52. D. Ruan, F. Hardeman, K. van der Meer, Eds., Intelligent Decision and Policy Making Support Systems, Springer, Heideberg, 2008

53. D.L. Xu, J.B. Yang, B. Carlé, F. Hardeman, D. Ruan, Application of an intelligent decision system to nuclear waste repository option analysis, Int. J. Nuclear Governance, Economy and Ecology, 2 (2), 145-165 (2008) 